\title{
Endoscopic Laryngeal Findings in Japanese Patients with Laryngopharyngeal Reflux Symptoms
}

\author{
Nobuhiko Oridate, ${ }^{1}$ Ryoji Tokashiki, ${ }^{2}$ Yusuke Watanabe, ${ }^{3}$ Aki Taguchi, ${ }^{4}$ \\ Osamu Kawamura, ${ }^{5}$ and Kazuma Fujimoto ${ }^{6}$ \\ ${ }^{1}$ Department of Otolaryngology-Head and Neck Surgery, Hokkaido University Graduate School of Medicine, Kita 15, Nishi 7, \\ Kita-ku, Sapporo 060-8638, Japan \\ ${ }^{2}$ Department of Otolaryngology, Tokyo Medical University, Tokyo 160-0023, Japan \\ ${ }^{3}$ Department of Otorhinolaryngology, International University of Health and Welfare Mita Hospital, Tokyo 108-8329, Japan \\ ${ }^{4}$ Department of Otolaryngology, Ehime University Graduate School of Medicine, Ehime 791-0295, Japan \\ ${ }^{5}$ Department of Gastroenterology, Gunma University Hospital, Maebashi, Gunma 371-8511, Japan \\ ${ }^{6}$ Department of Internal Medicine, Saga Medical School, Saga 849-8501, Japan
}

Correspondence should be addressed to Nobuhiko Oridate, noridate@med.hokudai.ac.jp

Received 29 July 2011; Accepted 16 September 2011

Academic Editor: Wolfgang Issing

Copyright (C) 2012 Nobuhiko Oridate et al. This is an open access article distributed under the Creative Commons Attribution License, which permits unrestricted use, distribution, and reproduction in any medium, provided the original work is properly cited.

Objective. To know the characteristics of endoscopic laryngeal and pharyngeal abnormalities in Japanese patients with laryngopharyngeal reflux symptoms (LPRS). Methods. A total of 146 endoscopic images of the larynx and pharynx (60 pairs for the rabeprazole group and 13 pairs for the control group) were presented to 15 otolaryngologists blinded to patient information and were scored according to several variables potentially associated with laryngopharyngeal reflux. The median value of the 15 scores for each item from each image was obtained. The mean pretreatment scores of each item and total score were assessed in both rabeprazole and control groups. In the rabeprazole group, the endoscopic findings before and after the 4-week treatment with rabeprazole were compared. Changes between corresponding duration in the control group were also evaluated. Results. The median and mean pretreatment total score was 3 and 3.02, respectively, from the 73 patients with LPRS. No significant differences were observed before and after treatment in either the rabeprazole or control groups for any item or total score. In 24 patients with a high pretreatment score (total score $\geq 4$ ) from the rabeprazole group, significant decreases in scores for "thick endolaryngeal mucous" (0.54 to 0.17 , $P=0.017)$ and total $(4.77$ to $3.58, P=0.0003)$ were observed after the 4 -week treatment.

\section{Introduction}

Gastroesophageal reflux is a recognized cause of ENT symptoms [1]. Laryngopharyngeal symptoms and signs were referred to as laryngopharyngeal reflux (LPR) [2]. The laryngopharyngeal findings attributed to gastroesophageal reflux have been reported in the posterior pharyngeal wall, true vocal folds, and arytenoid medial wall [3]. However, accurate assessment of signs in the larynx and pharynx is likely to be difficult because these signs observed during a laryngoscopic examination cannot be reliably determined from clinician to clinician [4]. The sensitivity and specificity of laryngopharyngeal findings, therefore, remain uncertain, challenging the diagnostic accuracy of LPR. In this study, we con- ducted a multicenter clinical trial to explore the presence of endoscopic laryngeal findings in Japanese patients with laryngopharyngeal reflux symptoms (LPRSs). Because the firstline therapy for LPRS is considered to be proton pump inhibitor (PPI) [2], we also compared the endoscopic laryngeal findings before and after a 4 -week acid suppression therapy.

\section{Methods}

Subjects consisted of outpatients visiting the otolaryngology departments of participating institutions between October 2007 and May 2008 who had at least one LPRS such as lump in the throat, throat pain, irritation in the throat, chronic 
TABLE 1: Score for endoscopic laryngeal findings used in this study.

\begin{tabular}{llllll}
\hline Findings & \multicolumn{5}{c}{ Score } \\
\hline Infraglottic edema with pseudosulcus formation & 0 & 1 & 2 & 3 & $\mathrm{NE}$ \\
Laryngeal mucosa ledema & 0 & 1 & 2 & 3 & $\mathrm{NE}$ \\
Posterior commissure hypertrophy & 0 & 1 & 2 & 3 & $\mathrm{NE}$ \\
Granulation formulation & 0 & 1 & 2 & 3 & $\mathrm{NE}$ \\
Thick endolaryngeal mucous & 0 & 1 & 2 & 3 & $\mathrm{NE}$ \\
Redness in the intra-arythenoid medial wall & 0 & 1 & 2 & 3 & $\mathrm{NE}$ \\
Mucous pooling in the pyriform sinus & 0 & 1 & 2 & 3 & $\mathrm{NE}$ \\
\hline
\end{tabular}

NE: not evaluable.

TABLE 2: Mean scores for pretreatment endoscopic findings $(n=$ 73).

\begin{tabular}{lllll}
\hline Endoscopic findings & $\begin{array}{l}\text { Total } \\
(n=73)\end{array}$ & $\begin{array}{l}\mathrm{RPZ} \\
(n=60)\end{array}$ & $\begin{array}{l}\text { Control } \\
(n=13)\end{array}$ & $P$-value \\
\hline $\begin{array}{l}\text { Infraglottic edema } \\
\text { with pseudosulcus } \\
\text { formation }\end{array}$ & 0.39 & 0.40 & 0.35 & 0.776 \\
\hline $\begin{array}{l}\text { Laryngeal mucosa } \\
\text { edema }\end{array}$ & 0.52 & 0.50 & 0.62 & 0.471 \\
\hline $\begin{array}{l}\text { Posterior } \\
\text { commissure } \\
\text { hypertrophy }\end{array}$ & 0.83 & 0.88 & 0.62 & 0.106 \\
\hline $\begin{array}{l}\text { Granulation } \\
\text { formulation }\end{array}$ & 0.15 & 0.17 & 0.08 & 0.362 \\
\hline $\begin{array}{l}\text { Thick endolaryngeal } \\
\text { mucous }\end{array}$ & 0.22 & 0.23 & 0.15 & 0.523 \\
\hline $\begin{array}{l}\text { Redness in the } \\
\text { intra-arythenoid } \\
\text { medial wall }\end{array}$ & 0.49 & 0.53 & 0.31 & 0.153 \\
\hline $\begin{array}{l}\text { Mucous pooling in } \\
\text { the pyriform sinus }\end{array}$ & 0.43 & 0.43 & 0.42 & 0.968 \\
\hline \begin{tabular}{l} 
Total \\
\hline
\end{tabular} & 3.02 & 3.13 & 2.54 & 0.258 \\
\hline
\end{tabular}

cough, and hoarseness and whose consent could be obtained. A total of 255 endoscopic laryngeal images were presented to 15 otolaryngologists listed in the appendix with the subjects' names and their before and after therapy status blinded. The 15 otolaryngologists individually scored on a four-point scale as 0 (none), 1 (mild), 2 (moderate), and 3 (severe) or NE (not evaluable) for findings potentially associated with LPR, as shown in Table 1. First 5 of 7 items are derived from the Reflux Finding Score proposed by Belafsky et al. [5] and the other 2 were from the report by Vaezi et al. [3].

Of the 255 images, 109 were excluded (95, patient overlap; 14, number of NE items > 3), and the remaining 146 images were used for further analysis. The median value of the 15 scores for each item from each subject was obtained. The mean pretreatment scores of each item and total scores were assessed. Examples for the images with high (total score: 7) and low (total score: 0) median scores were shown in Figures 1(a) and 1(b), respectively. To 60 patients who were considered for indication of acid suppression therapy based on their symptoms, $10 \mathrm{mg} /$ day of rabeprazole (RPZ) for 4 weeks was administered and the endoscopic findings before and after the 4-week treatment with RPZ were compared.
TABLE 3: Endoscopic findings before and after 4 weeks in the control group $(n=13)$.

\begin{tabular}{|c|c|c|c|}
\hline Endoscopic findings & Initial & $\begin{array}{l}4 \text { weeks } \\
\text { later }\end{array}$ & $P$-value \\
\hline $\begin{array}{l}\text { Infraglottic edema with } \\
\text { pseudosulcus formation }\end{array}$ & 0.35 & 0.46 & 0.570 \\
\hline Laryngeal mucosa edema & 0.62 & 0.77 & 0.337 \\
\hline $\begin{array}{l}\text { Posterior commissure } \\
\text { hypertrophy }\end{array}$ & 0.62 & 0.62 & 1.000 \\
\hline Granulation formulation & 0.08 & 0.08 & 1.000 \\
\hline $\begin{array}{l}\text { Thick endolaryngeal } \\
\text { mucous }\end{array}$ & 0.15 & 0.31 & 0.337 \\
\hline $\begin{array}{l}\text { Redness in the } \\
\text { intra-arythenoid medial } \\
\text { wall }\end{array}$ & 0.31 & 0.15 & 0.337 \\
\hline $\begin{array}{l}\text { Mucous pooling in the } \\
\text { pyriform sinus }\end{array}$ & 0.42 & 0.50 & 0.838 \\
\hline Total & 2.54 & 3.00 & 0.239 \\
\hline
\end{tabular}

TABle 4: Pre- and posttreatment endoscopic findings in the RPZ group $(n=60)$.

\begin{tabular}{llll}
\hline Endoscopic findings & Pretreatment & Post-treatment & $P$-value \\
\hline $\begin{array}{l}\text { Infraglottic edema } \\
\text { with pseudosulcus } \\
\text { formation }\end{array}$ & 0.40 & 0.33 & 0.419 \\
\hline $\begin{array}{l}\text { Laryngeal mucosa } \\
\text { edema }\end{array}$ & 0.50 & 0.59 & 0.268 \\
\hline $\begin{array}{l}\text { Posterior commissure } \\
\text { hypertrophy }\end{array}$ & 0.88 & 0.98 & 0.147 \\
\hline $\begin{array}{l}\text { Granulation } \\
\text { formulation }\end{array}$ & 0.17 & 0.18 & 0.709 \\
\hline $\begin{array}{l}\text { Thick endolaryngeal } \\
\text { mucous }\end{array}$ & 0.23 & 0.15 & 0.279 \\
\hline $\begin{array}{l}\text { Redness in the } \\
\text { intra-arythenoid } \\
\text { medial wall }\end{array}$ & 0.53 & 0.62 & 0.273 \\
\hline $\begin{array}{l}\text { Mucous pooling in } \\
\text { the pyriform sinus }\end{array}$ & 0.43 & 0.37 & 0.279 \\
\hline \begin{tabular}{l} 
Total \\
\hline
\end{tabular} & 3.13 & 3.20 & 0.779 \\
\hline
\end{tabular}

Changes between corresponding duration in 13 patients, who had at least one LPRS and had not received acid suppression therapy, were also evaluated. Double-sided paired or unpaired $t$-tests were used to test the significance of differences.

\section{Results}

The pretreatment total score for all 73 subjects ranged from 0 to 7 (median score 3, mean score 3.02). No significant differences were observed between the groups for any item or total score (RPZ group: 3.12; control group: 2.54, Table 2). Further, no significant differences were observed before and after treatment in either the RPZ or control groups for any item or total score (Tables 3 and 4). In 24 patients with a high 


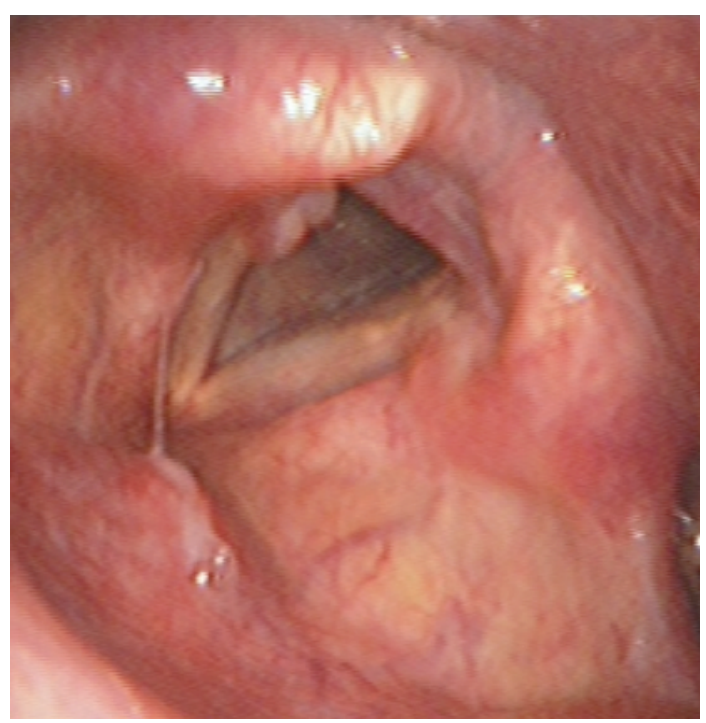

(a)

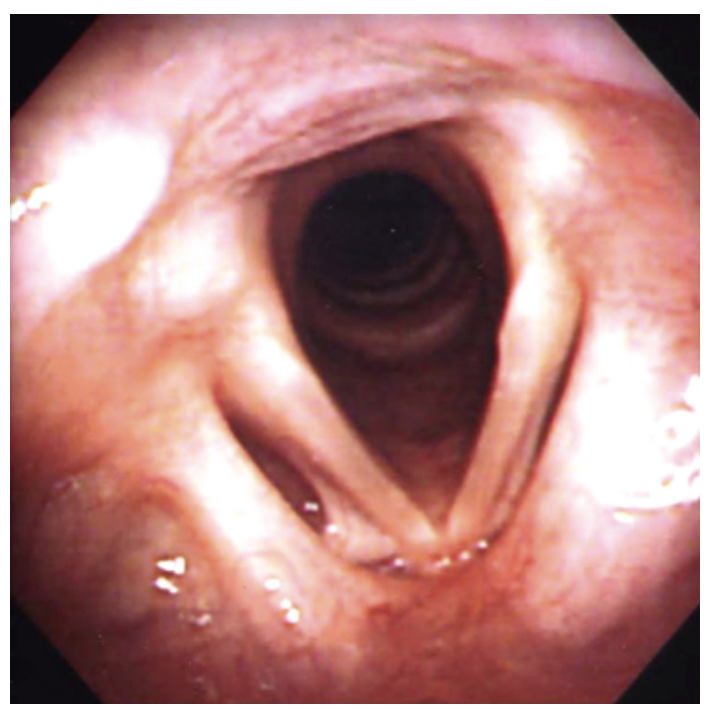

(b)

FIGURE 1: Examples for endoscopic laryngeal images with (a) a high score (total score: 7) and (b) a lowest score (total score: 0 ).

TABle 5: Pre- and post-treatment endoscopic findings in patients with a total score $\geq 4$ from the RPZ group $(n=24)$.

\begin{tabular}{llll}
\hline Endoscopic findings & Pretreatment & Post-treatment & $P$-value \\
\hline $\begin{array}{l}\text { Infraglottic edema } \\
\text { with pseudosulcus } \\
\text { formation }\end{array}$ & 0.58 & 0.38 & 0.203 \\
\hline $\begin{array}{l}\text { Laryngeal mucosa } \\
\text { edema }\end{array}$ & 0.79 & 0.65 & 0.307 \\
\hline $\begin{array}{l}\text { Posterior commissure } \\
\text { hypertrophy }\end{array}$ & 1.10 & 0.96 & 0.166 \\
\hline $\begin{array}{l}\text { Granulation } \\
\text { formulation }\end{array}$ & 0.29 & 0.29 & 1.000 \\
\hline $\begin{array}{l}\text { Thick endolaryngeal } \\
\text { mucous }\end{array}$ & 0.54 & 0.17 & 0.017 \\
\hline $\begin{array}{l}\text { Redness in the } \\
\text { intra-arythenoid } \\
\text { medial wall }\end{array}$ & 0.83 & 0.73 & 0.396 \\
\hline $\begin{array}{l}\text { Mucous pooling in } \\
\text { the pyriform sinus }\end{array}$ & 0.63 & 0.42 & 0.135 \\
\hline \begin{tabular}{l} 
Total \\
\hline
\end{tabular} & 4.77 & 3.58 & 0.0003 \\
\hline
\end{tabular}

pretreatment score (total score $\geq 4$ ) from the RPZ group, significant decreases in scores for "thick endolaryngeal mucous" ( 0.54 to $0.17, P=0.017$ ) and total ( 4.77 to $3.58, P=0.0003$ ) were observed after the 4 -week treatment (Table 5).

\section{Discussion}

The precise laryngoscopic diagnosis of LPR is likely to be difficult because the examination of abnormalities in the larynx and the pharynx could be highly subjective [4]. Even with using gastrointestinal endoscopy which provides clear images with higher resolution than laryngoscopy, diagnostic value was limited when evaluating these laryngopharyngeal lesions in patients with gastroesophageal reflux [6]. Some authors emphasize these findings in the larynx and pharynx as being specific for acid-related problems, others argue that these may be secondary to other factors such as smoking, allergies, asthma, viral illness, and voice abuse $[3,7,8]$.

During our daily practice in the ENT clinics, we noticed that most of Japanese patients who complain a typical constellation of LPRS do not necessarily exhibit such laryngopharyngeal abnormal findings. We also noticed that minimal changes of these findings are very difficult to be documented objectively. These small abnormalities cannot be revealed due to the consideration to examiner bias $[4,6]$. We performed this study to ensure objectivity to some extent of the examination of abnormalities in the larynx and pharynx in this patient population. We presumed that the median value of 15 otolaryngologists was the most appropriate value of each finding of the laryngopharyngeal abnormality. We then found a low pretreatment score among the Japanese patients with LPRS, suggesting that most of them had only mild laryngeal signs. When limited to the patients with a high endoscopic laryngeal score, a significant decrease in total score was observed after acid-suppression therapy.

There are some limitations in this study. Among them, the major one would be the length and the dose of PPI treatment. These could be a possible reason for causing no significant difference before and after the RPZ treatment. The 4 weeks of acid suppression with RPZ with a dose of $10 \mathrm{mg} /$ day may not be long or strong enough to see objective improvement. Ford proposed an empirical therapeutic trial using double-dose, twice-daily PPI for three months [2], suggesting that both the length and the dose of PPI treatment in this study were not enough to observe significant changes in the laryngopharyngeal findings.

Currently, only the patients with obvious laryngopharyngeal abnormalities were recruited to the prospective, randomized, double-blind and placebo-controlled studies on 
the effect of PPI on symptom improvement $[9,10]$. In Lam's report, there were no significant differences in laryngopharyngeal findings between the PPI and placebo groups, suggesting that the improvement in laryngeal signs might not lead to significant improvement in patient symptoms. In other words, laryngeal signs may not correlate faithfully with actual improvement in LPRS. It may be possible to postulate that the effect of PPI is not limited to the patients with obvious laryngopharyngeal abnormalities. The correlation between laryngopharyngeal symptoms and signs would need further studies. Because the precise diagnosis of LPR is still difficult, it is of critical importance to identify morphologic or physiologic features more specific for LPR.

\section{Conclusions}

The low pretreatment total score of the Japanese patients with LPRS suggested that most of them had only mild objective laryngeal signs. In LPRS patients with a high endoscopic laryngeal score, a significant decrease in total score was observed after acid suppression therapy.

\section{Appendix}

Fifteen otolaryngologists who evaluated endoscopic laryngeal images: Nobuhiko Oridate, Yasushi Mesuda, Masanobu Suzuki (Hokkaido University Hospital), Tomoko Shintani, Etsuko Kanaizumi (Sapporo Medical University Hospital), Aya Maruko (Jusendo Hospital), Yusuke Watanabe (International University of Health and Welfare Mita Hospital), Ryoji Tokashiki (Tokyo Medical University Hospital), Yuki Hamashima, Masanori Yoshioka (Nagoya City University Hospital), Kiyoto Hosokawa (Kansai Rousai Hospital), Aki Taguchi (Ehime University Hospital), Rieko Gotoh, Kanako Indoh (Kagawa University Hospital), and Misako Yamamoto (Sanuki Municipal Hospital).

\section{Acknowledgment}

This study was partially supported by Eisai Co., Ltd.

\section{References}

[1] N. Vakil, S. V. van Zanten, P. Kahrilas et al., “The Montreal definition and classification of gastroesophageal reflux disease: a global evidence-based consensus," American Journal of Gastroenterology, vol. 101, no. 8, pp. 1900-1920, 2006.

[2] C. N. Ford, "Evaluation and management of laryngopharyngeal reflux," Journal of the American Medical Association, vol. 294, no. 12, pp. 1534-1540, 2005.

[3] M. F. Vaezi, D. M. Hicks, T. I. Abelson, and J. E. Richter, "Laryngeal signs and symptoms and gastroesophageal reflux disease (GERD): a critical assessment of cause and effect association," Clinical Gastroenterology and Hepatology, vol. 1, no. 5, pp. 333-344, 2003.

[4] R. C. Branski, N. Bhattacharyya, and J. Shapiro, "The reliability of the assessment of endoscopic laryngeal findings associated with laryngopharyngeal reflux disease," Laryngoscope, vol. 112, no. 6, pp. 1019-1024, 2002.
[5] P. C. Belafsky, G. N. Postma, and J. A. Koufman, "The validity and reliability of the reflux finding score (RFS)," Laryngoscope, vol. 111, no. 8, pp. 1313-1317, 2001.

[6] S. R. Vavricka, C. A. Storck, S. M. Wildi et al., "Limited diagnostic value of laryngopharyngeal lesions in patients with gastroesophageal reflux during routine upper gastrointestinal endoscopy," American Journal of Gastroenterology, vol. 102, no. 4, pp. 716-722, 2007.

[7] J. A. Koufman, "The otolaryngologic manifestations of gastroesophageal reflux disease (GERD): a clinical investigation of 225 patients using ambulatory 24 -hour $\mathrm{pH}$ monitoring and an experimental investigation of the role of acid and pepsin in the development of laryngeal injury," Laryngoscope, vol. 101, no. 4, pp. 1-7, 1991.

[8] J. E. Richter and D. M. Hicks, "Unresolved issues in gastroesophageal reflux-related ear, nose, and throat problems," American Journal of Gastroenterology, vol. 92, no. 12, pp. 2143-2144, 1997.

[9] P. K. Y. Lam, M. L. Ng, T. K. Cheung et al., "Rabeprazole is effective in treating laryngopharyngeal reflux in a randomized placebo-controlled trial," Clinical Gastroenterology and Hepatology, vol. 8, no. 9, pp. 770-776, 2010.

[10] O. Reichel, H. Dressel, K. Wiederänders, and W. J. Issing, "Double-blind, placebo-controlled trial with esomeprazole for symptoms and signs associated with laryngopharyngeal reflux," Otolaryngology_Head and Neck Surgery, vol. 139, no. 3, pp. 414-420, 2008. 


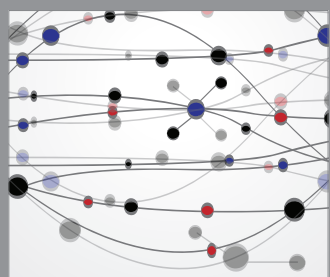

The Scientific World Journal
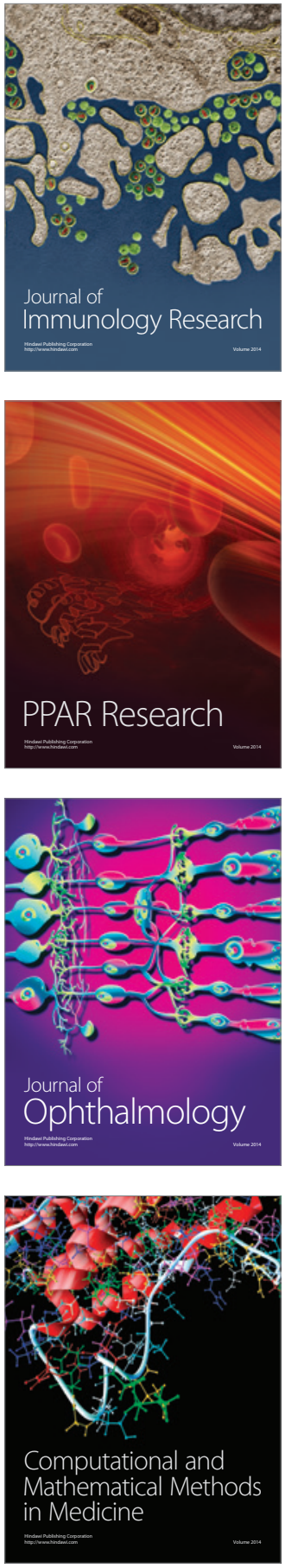

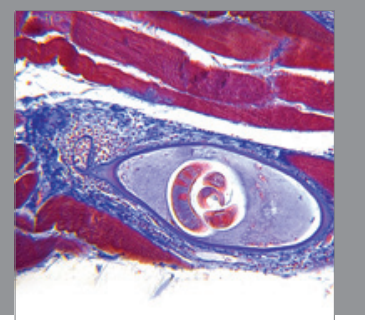

Gastroenterology

Research and Practice
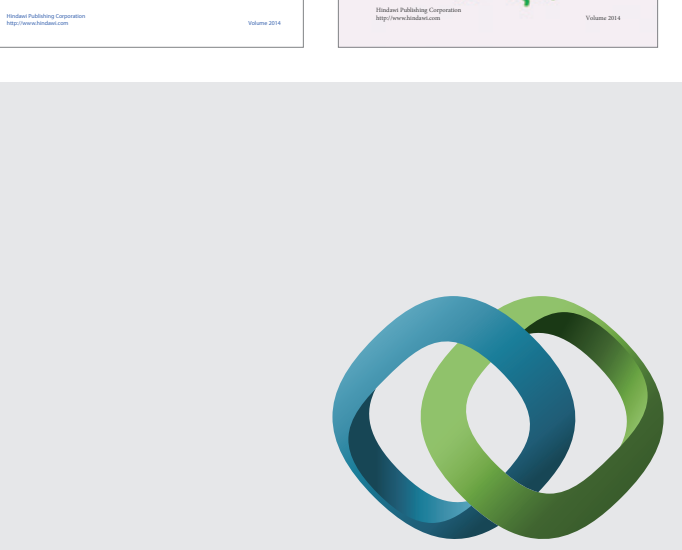

\section{Hindawi}

Submit your manuscripts at

http://www.hindawi.com
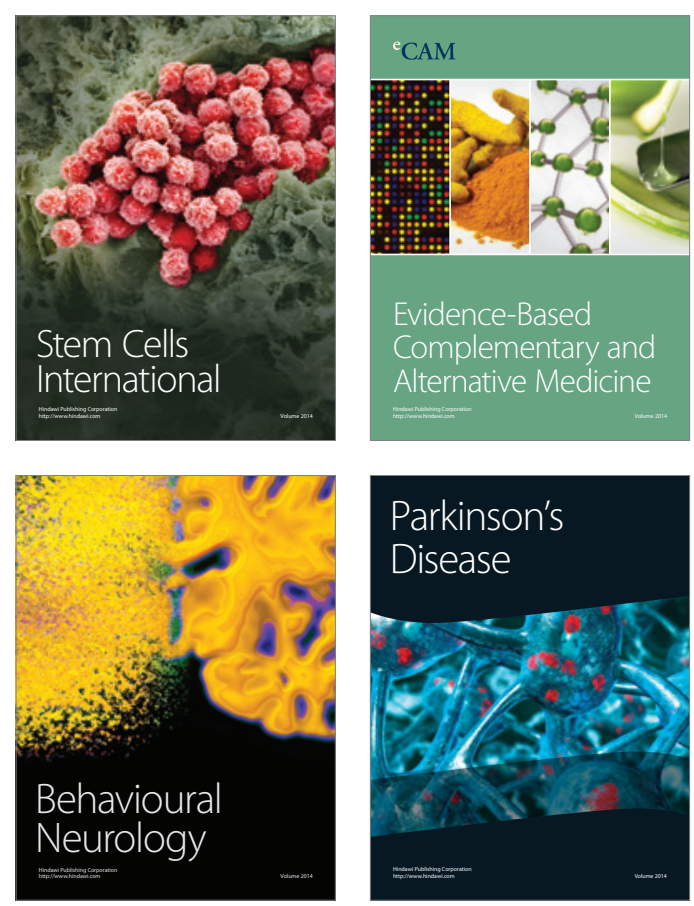

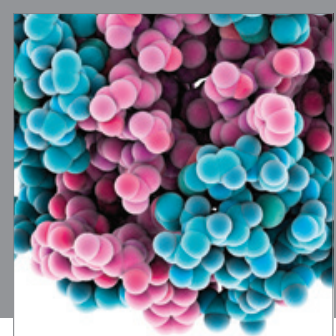

Journal of
Diabetes Research

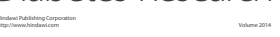

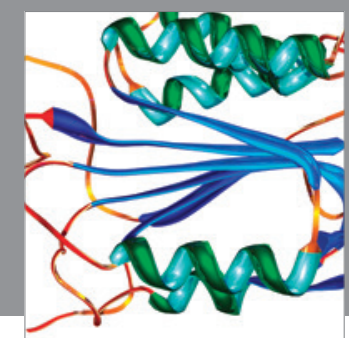

Disease Markers
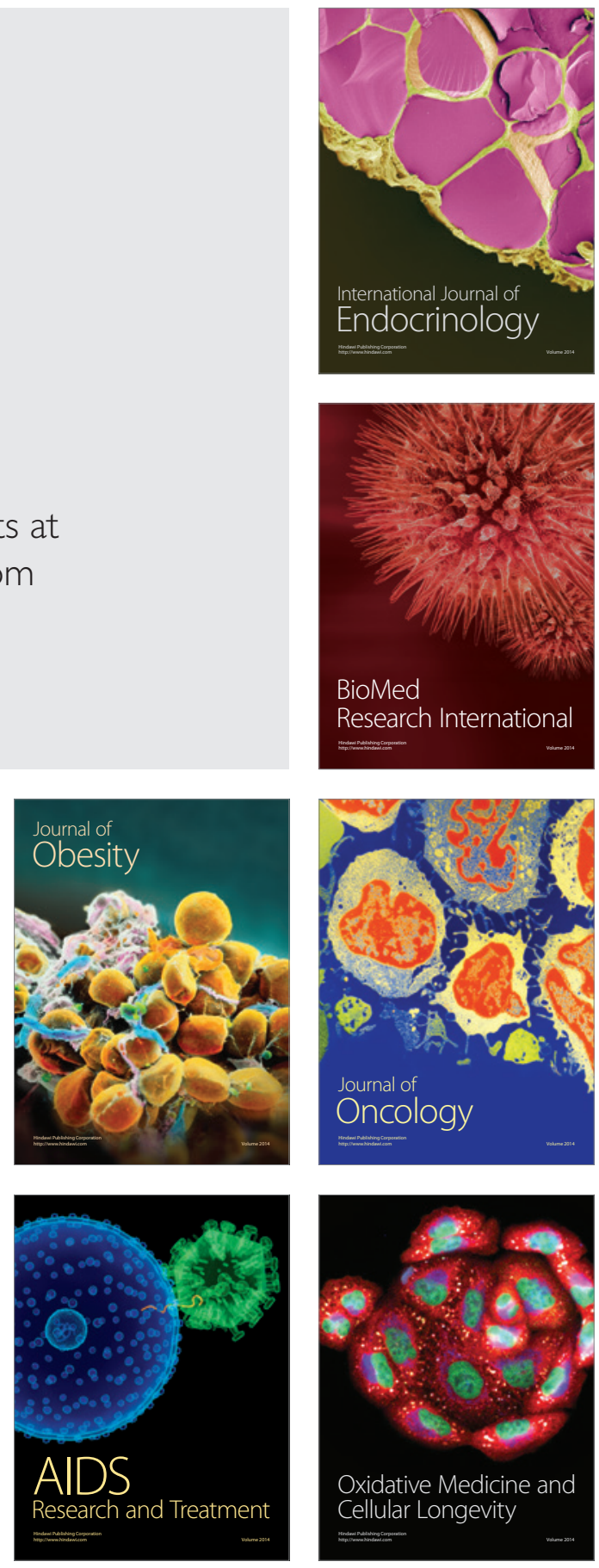